\title{
Real-time Magnetic Observatory Network: A Review
}

\author{
Jyh-Woei Lin
}

ABSTRACT

The International Real-time Magnetic Observatory Network (INTERMAGNET) was based on the Observatory Instruments in Ottawa, Canada in August 1986. After coordination between the United States and British Geological Surveys, this network could use to record Earth's magnetic field e.g., Disturbance storm time (Dst) index that monitored a large geomagnetic storm. The INTERMAGNET has been used in to access the observed communicating. The production of geomagnetic products could be obtained in real-time. Overseeing the operations of INTERMAGNET, the first geomagnetic Information Node (GIN) was established in 1991, the first CD-ROM/DVD was published in 1991.

Keywords: Earth's magnetic field; International Real-time Magnetic Observatory Network (INTERMAGNET); Observatory Instruments.

Published Online: September 16, 2021

ISSN: $2684-446 \mathrm{X}$

DOI : $10.24018 /$ ejgeo.2021.2.5.177

\section{Jyh-Woei Lin*}

Binjiang College, Nanjing University of Information Science \& Technology, Wuxi, 214105, Jiangsu Province, China. Department of Electrical Engineering, Southern Taiwan University of Science and Technology, Tainan, Taiwan.

(e-mail: pgjw11966@gmail.com)

*Corresponding Author

\section{INTRODUCTION}

Recently, space weather e.g., geomagnetic storm, is an important topic [1.], [2]. For example, a large geomagnetic storm could cause economic losses [3]. The data of Earth's magnetic field are necessary to be recorded almost in realtime [4]. The variants of Earth's magnetic field indicate a part of space weather [5]. Therefore, the International Real-time Magnetic Observatory Network (INTERMAGNET) is based on the Observatory Instruments in Ottawa, Canada in August 1986 with the ground-based magnetometers throughout the world, as per Fig. 1. After coordination between the United States and British Geological Surveys, this network is used to record Earth's magnetic field e.g., Disturbance storm time (Dst) index [5]. The GOES East satellite successfully transferred geomagnetic data between the two organisations [6]. Fig. 2 shows Artist's conception of the GOES-13 satellite. The INTERMAGNET was used in to access the observed communicating. Overseeing the operations of INTERMAGNET, the first geomagnetic Information Node (GIN) was established in 1991, the first CD-ROM/DVD was published in 1991.

\section{DISCUSSION}

INTERMAGNET is an observation system, which provides Earth's magnetic field data that supports research into the earth, from its earth surface to space. Especially geomagnetic storms are monitored through the variants of Dst index. When the magnitude of the Dst index varies to the extremely small negative, then a large geomagnetic storm is indicated in Fig. 3 [5], [7]-[9]. Fig 3. plots the Dst indices in November 2001. The negative Dst indices can describe the detailed features of a geomagnetic storm on 05 November. It caused by a fast-moving CME triggered vivid aurorae as far south as Texas, California, and Florida. For the worldwide membership, INTERMAGNET supplies consistent data with the aim of the geographical experiments, research and applied science.

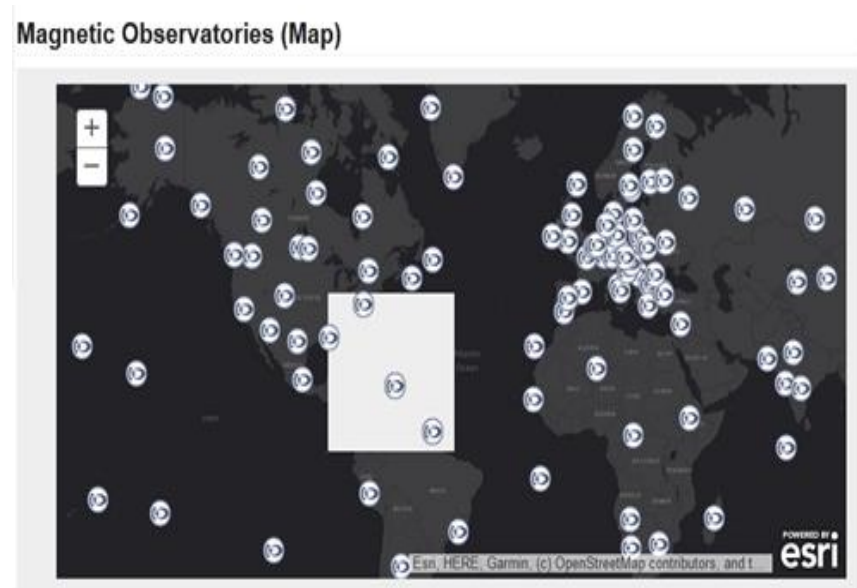

Fig.1. A large number of geomagnetic observatories throughout the world are members of INTERMAGNET (Source: [10]).

\section{CONCLUSIONS}

The INTERMAGNET was based on the Observatory Instruments in Ottawa, Canada in August 1986. The INTERMAGNET served as important observation system, which has been used to establish a global network of magnetic observatories for measured and recorded equipment, in order to facilitate data exchanges and the production of geomagnetic products was obtained in close to real time. For example, it has been used to record Disturbance storm time (Dst) index that monitored a large geomagnetic storm. Overseeing the operations of INTERMAGNET, the first geomagnetic Information Node (GIN) was established in 1991, the first CD-ROM/DVD was published in 1991. 

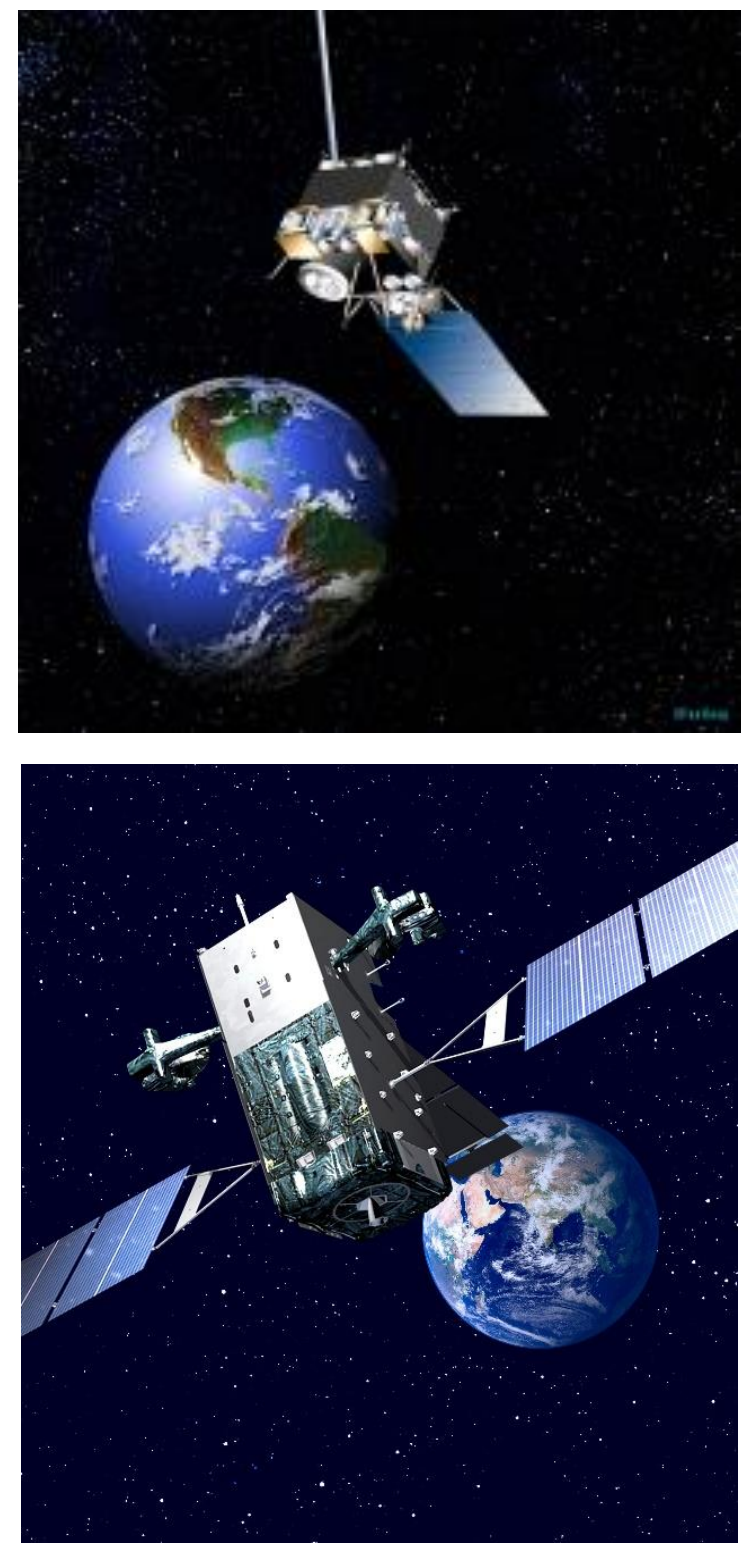

Fig. 2. Artist's conception of the GOES-13 satellite (Source: National Aeronautics and Space Administration, NASA).

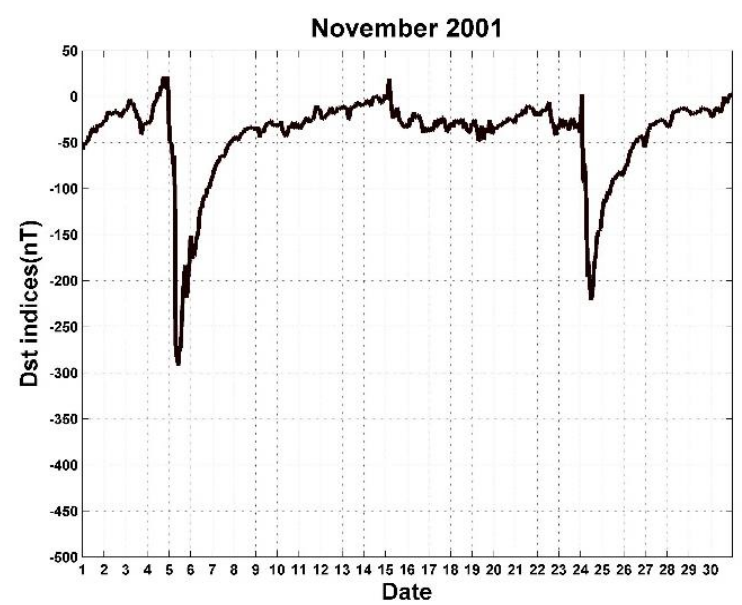

Fig. 3. Plot of Dst indices for November 2001 (Source: World Data Center for Geomagnetism, Kyoto). The negative Dst indices can describe the detailed features of a geomagnetic storm on 05 November.

It caused by a fast-moving CME triggered vivid aurorae as far south as Texas, California, and Florida.

\section{ACKNOWLEDGMENT}

The author is grateful to the World Data Centre for Geomagnetism, Kyoto; the geomagnetic observatories and National Oceanic and Atmospheric Administration (NOAA).

The author is also grateful the supporting of Prof. Dr Yuan Mei in Taiwan and all of my friends in Taiwan and China

\section{CONFLICTS OF INTEREST}

The author declares that there is no conflict of interest.

\section{REFERENCES}

[1] D. N. Baker, "What is space weather?," Advances in Space Research, vol. 22, no. 1, pp. 7-16, 1998, doi: 10.1016/S0273-1177(97)01095-8.

[2] R. Jain., M. Aggarwal and R. Sharma, "X-ray emission from solar flares," Journal of Astrophysics and Astronomy, vol. 29, no. 1, pp. 125145, 2008. doi: 10.1007/s12036-008-0016-z.

[3] J.P. Eastwood, E. Biffis., M.A. Hapgood, L. Green, M.M. Bisi, R.D. Bentley, R. Wicks, L.A. McKinnell, M. Gibbs and C. Burnett, "The Economic Impact of Space Weather: Where Do We Stand?," Risk Analysis, vol. 37, no. 2, pp. 206-218, 2017. doi:10.1111/risa.12765.

[4] J.W. Lin, "Magnetic Field Measurements by the Satellite Systems: A Review," European Journal of Environment and Earth Sciences, vol. 2, no. 4, pp. 35-36, 2021. doi: 10.24018/ejgeo.2021.2.4.153.

[5] K. Mursula, L. Holappa, and A. Karinen., "Correct normalization of the Dst index," Astrophysics and Space Sciences Transactions, vol. 4, no. 2, pp. 41-45, 2008. doi: 10.5194/astra-4-41-2008.

[6] https://www.nasa.gov/mission_pages/goes-n/media/goes-east.html.

[7] H.S. Jones, "Geomagnetism, 1st Edition," Annals of the International Geophysical Year, vol. 4, Elsevier, pp. 197, 2008. ISBN: 9781483226477.

[8] W.H. Campbell, "Geomagnetic storms, the Dst ring-current myth and lognormal distributions," Journal of Atmospheric and Terrestrial Physics, vol. 58, no. 10, pp. 1171-1187, 1996. doi: 10.1016/00219169(95)00103-4

[9] M. Jawad, A. Rafique, I. Khosa., I. Ghous, J. Akhtar and S.M. Ali, "Improving Disturbance Storm Time Index Prediction Using Linear and Nonlinear Parametric Models: A Comprehensive Analysis," IEEE Transactions on Plasma Science, vol. 47, no. 2, pp. 1429-1444, 2019. doi: 10.1109/TPS.2018.2887202.

[10] https://intermagnet.github.io/.

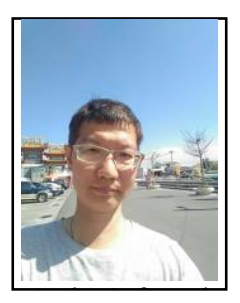

Jyh-Woei Lin received the B.Sc. degree from the Department of Physics, Chung Yuan Christian University, Chung Li City, Taiwan, in 1989, the M.Sc. degree from the Institute of Geophysics, National Central University, Chung Li City, in 1991, the Ph.D. degree from the Institut für Geophysik, Clausthal-Zellerfeld, Technische Universit ät Clausthal, Germany, in 2000, and the Ph.D. degree from the Department of Electrical Engineering, Southern Taiwan University of Science and Technology, Tainan, Taiwan, in 2019. Since 2019, he is a researcher in the Department of Electrical Engineering, Southern Taiwan University of Science and Technology. Until 2021, he has 71 SCI (SCIE) and EI papers include artificial intelligence, space physics, geophysics, medical sciences, and remote sensing; especially four books' publications in Germany and two books in USA. After September 2020, he is as a Professor in Binjiang College, Nanjing University of Information Science \& Technology, Wuxi, Jiangsu Province, China. 